\title{
Sarampión: antecedentes históricos y situación actual
}

\author{
Measles: historical background and current situation
}

\author{
Ricardo Fadic R. ${ }^{\text {a }}$, Guillermo Repetto D. ${ }^{\text {b }}$
}

alnterno, Carrera de Medicina, Facultad de Medicina Clínica Alemana Universidad del Desarrollo

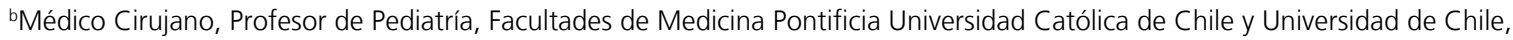

Recibido el 25 de abril de 2019; aceptado el 3 de mayo de 2019

\begin{abstract}
Resumen
El sarampión sigue siendo una causa importante de morbilidad y mortalidad en el niño. Durante estos últimos años, se ha convertido en un problema de salud pública mundial, que se atribuye a bajas coberturas de vacunación observadas en diferentes países. Para su control se dispone de una vacuna a virus vivo, altamente eficaz, que fue empleada por primera vez en Chile en 1964, logrando cobertura en prácticamente todo el país en un breve plazo. Esta fue la primera experiencia mundial, imitada luego por otros países que resulto en una importante caída de las tasas de morbilidad y de mortalidad. Su eficacia ha sido ampliamente demostrada, pero requiere de la mantención de coberturas superiores a 95\%. En Chile persistió una situación de endemia de menor magnitud hasta el año 1993. En años recientes, ha habido algunos brotes reducidos y casos esporádicos vinculados a contactos con casos importados, sin embargo, según datos recientes, el sarampión está circulando ahora en más de 160 países en un nivel de propagación sin precedentes, siendo los viajeros infectados el principal vehículo de transmisión. En Chile, el Ministerio de Salud ha decidido reforzar y poner al día la vacunación de grupos susceptibles, en especial viajeros. En esta actualización se revisan aspectos históricos y la información actual de esta enfermedad que ha resurgido mostrando su alto impacto epidemiológico en la población pediátrica y adulta a nivel global.
\end{abstract}

\begin{abstract}
Measles is still a major cause of child morbidity and mortality. In recent years, it has become a global public health problem, attributed to low vaccination coverage observed in different countries. In order to control it, a highly effective live virus vaccine is available, which was used for the first time in Chile in 1964, covering practically the whole country in a short period of time. This was the first world experience, which was later imitated by other countries leading to a significant drop in morbidity and mortality rates. Its effectiveness has been amply demonstrated, but it requires coverage
\end{abstract}

Palabras clave: Sarampión; vacunas; historia medicina

\section{Keywords:}

Measles; Immunization; history of medicine 
maintenance higher than 95\%. In Chile, minor endemic situation persisted until 1993. In recent years, there have been some reduced outbreaks and sporadic cases linked to contacts with imported cases, however, according to recent data, measles is now circulating in more than 160 countries at an unprecedented spread level, where infected travelers are the main vehicle of transmission. In Chile, the Ministry of Health has decided to strengthen and update the vaccination of susceptible groups, especially travelers. This update reviews historical aspects and current information on this re-emerging disease, showing its high epidemiological impact on the pediatric and adult population globally.

\section{Introducción}

En el año 1959, incorporado en el Servicio de Pediatría del Hospital Regional de Concepción, recibí un llamado de un amigo, médico general de zona en $\mathrm{Cu}$ ranilahue, diciéndome que estaba siendo sobrepasado por la cantidad de pacientes de sarampión graves y con algunas muertes. Necesitaba con urgencia mi ayuda y no aceptaba, bajo ninguna circunstancia, mi negativa. Mi recuerdo más vívido fue al llegar al recinto hospitalario y ver pacientes de todas las edades, mujeres, hombres jóvenes y algunos mayores y mayoritariamente niños, con graves complicaciones de sarampión, hacinados en todos los espacios disponibles, incluidas salas de espera y pasillos. Los esfuerzos para paliar esta situación no fueron fáciles, con medios limitados que se agotaban rápidamente, sin posibilidades de traslado de pacientes a centros mejor dotados. Había urgencia de hidratar a los niños y adultos desnutridos con diarreas profusas, cuadros obstructivos bronquiales y empiemas pleurales.

Solo muchos años después logré comprender que la grave situación generada por un brote de sarampión en una comunidad relativamente aislada, y sin experiencia reciente previa con la enfermedad y, por lo tanto, con una población mayoritariamente susceptible a una infección de fácil y alta transmisibilidad.

Esta experiencia me hizo valorar la decisión de las autoridades que en 1964 iniciaron la vacunación de los niños del país, pese al elevado costo de la vacuna en esos años.

Han pasado 60 años de aquella epidemia, las noticias nos alertan de un nuevo brote de esta grave enfermedad que habíamos visto desaparecer. El objetivo del presente manuscrito es revisar la historia del sarampión y el impacto de la implementación de las campañas de vacunación.

\section{Historia}

El sarampión se conoce desde hace siglos: las primeras descripciones se atribuyen al médico hebreo Allyehudi en el siglo VII y al médico persa, Rhazes, quien vivió en el siglo X y la denominó "erupción”. En el siglo XVII, durante una grave epidemia en Londres, se notificaron separadamente el sarampión y la viruela, que hasta entonces eran estimadas una unidad. Thomas Sydenham, (1624-1689) describió sus características clínicas. A mediados del siglo XVII en Edimburgo, Francis Home (1720-1813) al reconocer su naturaleza infecciosa, intentó su prevención mediante una escarificación semejante a la que posteriormente realizaría Jenner en la viruela ${ }^{1}$. El conocimiento real de la enfermedad y de su epidemiología se debe al médico danés Peter Panum (1820-1885) quien, en 1846, describió una epidemia de sarampión en las islas Faroe y definió los periodos de incubación y transmisibilidad ${ }^{2}$. En 1911, Goldberger y Andersen demostraron la naturaleza infecciosa de la enfermedad, inyectando material obtenido desde pacientes en monos de laboratorio ${ }^{1}$.

A fines de 1899 hubo una epidemia de sarampión en Santiago de Chile, que luego se extendió a todo el país y continuó durante el año siguiente. Por su elevada mortalidad, el profesor Puga Borne llegó a señalar que "se nos había llevado una generación entera" Motivado por estos hechos, don Manuel Arriarán Barros fundó, a sus expensas, el primer hospital de niños del país ${ }^{3}$.

\section{Clínica}

En el sarampión infección y enfermedad son sinónimos, dado que la infección es siempre clínica. El reservorio es exclusivamente humano constituido por pacientes enfermos, no existiendo portadores asintomáticos ni participación del ambiente ni susceptibilidad generalizada. Su período de incubación es estable, de 11 días. La transmisibilidad del sarampión es muy elevada, especialmente en el período pre-eruptivo y en su desarrollo se distingue un período prodrómico caracterizado por signos catarrales de las vías respiratorias altas semejante a un resfrío común, conjuntivitis, fiebre progresiva y pápulas puntiformes en la mucosa oral (manchas de Koplik). A ello sigue un período eruptivo de tipo maculopapular que se inicia en la región mastoidea con rápida aparición en la cara y el res- 
to del cuerpo. El exantema regresa en el mismo orden en que apareció, dejando una coloración transitoria, en esta etapa se acentúa el compromiso general. El período de declinación dura unos seis días con desaparición de la fiebre y de los síntomas generales.

Las complicaciones determinan su gravedad. Las más frecuentes son diarrea aguda, otitis media, laringitis obstructiva y bronconeumonía que son las principales causas de muerte. Debido a que causa depresión de la inmunidad humoral y mediada por células, predispone a infecciones bacterianas que determinan su gravedad. Su notificación es obligatoria realizada por el médico y su omisión está penada por ley.

\section{La vacuna}

En el contexto de la creación de la vacuna, en 1954, John Enders y Thomas Peebles aislaron el virus causal en cultivos de células renales humanas ${ }^{4}$. Su adaptación posterior a medios con células embrionarias de pollo y células amnióticas humanas, seguida por atenuación mediante pasajes seriados en diferentes medios modificando la temperatura del cultivo, lográndose así la cepa denominada Edmonston, nombre del paciente en quien se logró el primer aislamiento. Las primeras vacunas inactivadas en Estados Unidos fueron definitivamente desechadas por su baja eficacia. Las vacunas con virus vivo atenuado reemplazaron a las vacunas inactivadas siendo las de mayor uso las Moraten, Schwarz, ASIK-C, Edmonston-Zagreb, entre otras. Una vacuna más atenuada de la cepa Edmonston (further attenuated vaccine) se empleó en Chile, sus reacciones secundarias son escasas, y su eficacia muy alta, pero es muy lábil y requiere estrictas exigencias de conservación y administración. Hasta antes de 1980 las vacunas empleadas eran termolábiles, actualmente se emplea liofilizadas.

La eficacia de la vacuna se fundamenta en estudios longitudinales epidemiológicos y serológicos realizado por Krugman, quien fue el primer investigador que demostró que los anticuerpos persistían por períodos muy prolongados, incluso por más de 30 años ${ }^{5}$. Los anticuerpos de origen transplacentarios de madres vacunadas persisten por períodos más breves que los derivados de las madres inmunizadas mediante infección natural ${ }^{5-8}$.

\section{Epidemiología}

El sarampión es una enfermedad viral, aguda, eruptiva, que en ausencia de vacunación es casi obligada en la infancia. Es de diagnóstico visual y habitualmente no requiere de apoyo de laboratorio. Sin embargo, como consecuencia de la vacunación, las nuevas generaciones de médicos carecen de la experiencia que permite su diagnóstico. Por ello se han propuesto criterios epidemiológicos con el fin de aumentar la sensibilidad de la pesquisa, siendo la principal manifestación el exantema, definiéndolos como:

Caso sospechoso/probable: El que presenta exantema eritematoso maculopapular que persiste durante tres o más días, fiebre previa o durante la erupción, tos, coriza, conjuntivitis o fotofobia.

Caso compatible: Paciente que ingresa al sistema de vigilancia pero no reúne los antecedentes necesarios para ser descartado o confirmado.

Caso confirmado: Paciente que cumple los criterios clínicos descritos y está ligado epidemiológicamente a otro caso probable o confirmado, o se demuestra serológicamente o por aislamiento viral.

Contacto: Toda persona que ha mantenido estrecho contacto con el caso durante el período infeccioso en el hogar u otro sito: esto es, 5 días antes y 5 días después de la erupción ${ }^{4,9,10}$.

Todo caso probable o confirmado, debe ser sometido a estricto aislamiento respiratorio y debe ser notificada inmediata a la Secretaria Regional Ministerial (SEREMI), porque es necesario tener en cuenta que nunca ocurren casos aislados.

Su transmisión es muy eficaz y ocurre directamente desde el enfermo vía aerosoles respiratorios y está limitado a los días que anteceden al periodo catarral e inicios del eruptivo. La tasa de ataque secundario de los contactos susceptibles en el hogar es superior al 95\%. Los principales factores que condicionan su gravedad son la desnutrición y la menor edad, ya que aumentan el riesgo de infecciones sobreagregadas.

Durante la epidemia ocurrida en Groenlandia en 1951, período en el que enfermó casi la totalidad de la población, el mayor porcentaje de muertes ocurrió en menores de un año, seis veces más que en los niños de 1 a 2 años y 53 veces más que en niños de 2 a 14 años ${ }^{4}$. Estos datos son semejantes a los descritos por Panum en la epidemia de las Islas Faroe ${ }^{2}$. En Chile, las tasas de mortalidad en el período pre-vacunación eran 100 veces mayores que en Austria y más elevada en los menores de 1 año (Tabla 1$)^{4}$. En Guatemala el riesgo era mayor en los niños entre 1 y 4 años y Colombia ocupaba una posición intermedia. La diferencia en la edad de presentación del cuadro entre los países se debía principalmente al tiempo de lactancia materna. Chile se caracterizaba por una lactancia materna breve y desnutrición precoz, mientras que en Guatemala era lactancia más prolongada y la desnutrición más tardía ${ }^{11}$.

En las décadas previas a la vacunación, se estimaba que el mayor número de muertes en el mundo, más de 2,5 millones e niños al año, mayoritariamente menores 
Tabla 1. Tasas de mortalidad por sarampión en niños menores de cinco años en países seleccionados. Promedio 1963-1964

\begin{tabular}{lcc}
\hline País & $\begin{array}{c}\text { Menores de 1 año por } \\
100.000 \text { nacidos vivos }\end{array}$ & $\begin{array}{c}1-4 \text { años } \\
\text { por 100.000 }\end{array}$ \\
\hline Austria & 4,5 & 2,2 \\
Inglaterra & 2,1 & 1,5 \\
Chile & 413,2 & 137,6 \\
Colombia & 61,9 & 48,8 \\
México & 71,0 & 103,7 \\
Guatemala & 248,0 & 310,0 \\
\hline
\end{tabular}

de un año, se debía al sarampión ${ }^{12}$. En 1991, la Oficina Panamericana de la Salud diseñó una estrategia de mantención de altos niveles de vacunación, a los 12 meses de edad y revacunación a los 4 o 6 años complementada en algunos países por campañas de vigilancia activa y por confirmación de los casos sospechosos con el apoyo de una Red Regional de Laboratorios ${ }^{4}$.

\section{La situación en Chile}

En el período pre vacunación, comprendido hasta aproximadamente 1950, las tasas de morbilidad y mortalidad eran relativamente estables $(60 / 100.000 \mathrm{y}$ $10 / 100.000$, respectivamente). A ello siguió un período de tasas de magnitud creciente; en 1961 la tasa de morbilidad se elevó a 493,2 /100.000 y la mortalidad a 38,9/100.000, dando cuenta aproximadamente de $3,5 \%$ de los decesos del país y $64 \%$ de los producidos por enfermedades trasmisibles ${ }^{13}$. Ello coincide con un período de industrialización del país, creciente migración del campo a la ciudad, déficit de viviendas, hacinamiento y cordones periféricos carentes de condiciones sanitarias básicas, lo que facilitó la difusión de las infecciones, en especial de sarampión ${ }^{14,15}$.

En septiembre de 1964 se inició la vacunación con una cepa viral, previamente autorizada en Estados
Unidos, en la provincia de Santiago continuando en los meses siguientes por el resto del país ${ }^{16}$. Esta fue la primera experiencia mundial de carácter nacional ${ }^{17}$.

Muy pronto cayeron las tasas de morbilidad y de mortalidad, en $93 \%$ y $99 \%$ respectivamente. La letalidad descendió desde $10 \%$ a $0,1 \%$, posiblemente influenciada por mejor atención médica, mejor cobertura y registro de casos. La vacunación a los 8 meses se incorporó en el calendario de vacunaciones en 1964 (tabla 2). En 1983, se postergó a los 12 meses, en concordancia con las recomendaciones internacionales ante la certeza de la total eliminación de anticuerpos pasivos de origen materno. En 1990, se implementó un esquema de administración de vacuna tres vírica (sarampión, parotiditis y rubeola). En 1992, se vacunaba a los 12 meses, con revacunación en el primer año básico.

El grupo más favorecido con la vacunación fue el de niños de edades entre 1 y 4 años, lo que contribuyó en forma importante a la caída de la mortalidad del párvulo y al efecto favorable de la postergación de la infección a edades mayores ${ }^{1}$.

En 1992, se logró la interrupción de la transmisión autóctona de la infección ${ }^{18}$. Persistía, sin embargo, una situación de endemia de menor magnitud interrumpida por brotes cada 3 a 4 años, que se explica por un remanente de susceptibles generados por coberturas insuficientes de vacunación, exigencia de conservación y manejo de las vacunas y, posiblemente por la persistencia de anticuerpos maternos residuales en los vacunados a los 8 meses.

En 1979 y 1988 hubo brotes de magnitud semejante a los del período pre vacunación ${ }^{3,4}$. En 1992 se efectuó una vacunación masiva de la población infantil. En 1992 y 1993 hubo un brote reducido que afectó a adultos en la zona rural de las Termas de Chillán iniciado por un instructor de esquí de Sao Paulo, 52\% de los afectados tenían edades entre 15 y 19 años y 15\% eran menores de un año ${ }^{12}$. En 1999 se notificaron dos casos. Hubo además un brote en Puerto Natales que afectó a 29 personas, y casos esporádicos que afectaron

Tabla 2. Esquemas de vacunación de sarampión por edad en Chile, según año

\begin{tabular}{cl}
\hline Año & Edad \\
\hline $1964-1979$ & 8 meses \\
$1980-1981$ & 8 meses y revacunación $2^{\circ}$ básico \\
1982 & 8 meses y entre los 18 meses a 4 años \\
$1983-1985$ & 12 meses y revacunación a los 18 meses para los vacunados antes de los 12 meses \\
$1986-1989$ & 12 meses \\
1990 & 12 meses con trivírica (sarampión, rubeola, parotiditis) y bivírica (sarampión-rubeola) en $4^{\circ}$ básico \\
1992-hasta hoy & 12 meses y revacunación en primero básico con trivírica \\
\hline
\end{tabular}


a turistas extranjeros. Estos afectaron a grupos etarios mayores de 20 años no protegidos por la vacuna. En el año 2011 hubo tres casos importados, uno de ellos transmitido por una azafata procedente de Brasil con la enfermedad y que en Santiago contagió a su hijo lactante y a su esposo de 35 años. Hubo casos esporádicos ocurridos en los años 1998, 1999, 2003, 2011 y 2015 relacionados con casos importados desde Tailandia ${ }^{12}$.

\section{Control versus erradicación}

El control o la erradicación del sarampión exigen mantener un nivel elevado de inmunidad. Los principales obstáculos para lograr este propósito derivan de algunas características de la enfermedad y de la vacuna, destacando su elevada transmisibilidad y la persistencia de la circulación viral en comunidades, incluso, con coberturas superiores a 95\% de vacunación, seguida de una acumulación progresiva de susceptibles no inmunizados. El virus aún circula en todo el mundo. Ha habido cambios en la epidemiologia de la infección, en los grupos de mayor riesgo, como niños mayores y adolescentes, y variaciones geográficas en los títulos de los anticuerpos pasivos de origen materno, que deben ser considerados en los programas de vigilancia ${ }^{19}$.

La vacuna, de elevada eficacia y casi total ausencia de contraindicaciones y reacciones secundarias, tiene como limitante su labilidad y requisitos de conservación y manejo. Los esquemas de vacunación de dos dosis, administrando la primera precozmente y la segunda a una edad en que se asegure conversión inmunológica, otorga inmunidad a niños no protegidos con la primera vacunación.

Asimismo, las campañas de vacunación están destinadas a disminuir el número de susceptibles manteniendo coberturas elevadas. La primera campaña que se realizó en Chile, estuvo concentrada en 10 días, en abril de 1992 en niños de 9 meses a 14 años y 11 meses de edad. En el año 1996 se repitió la vacunación masiva focalizada en los niños mayores de 1 años y menores de 15 años.

Las campañas de vacunación de "seguimiento", son un componente esencial de la estrategia para erradicación de la enfermedad. Estas campañas están dirigidas a todos los niños entre 1 a 4 años, 11 meses y 29 días, aunque ya estén vacunados o hayan tenido la enfermedad. Hasta el día de hoy, se han realizado en los años 2001, 2005 y 2010-2011.

A enero del 2019, se habían notificado 23 casos confirmados por el Instituto de Salud Pública ${ }^{17}$. Por lo que, en razón de los brotes recientes, el Ministerio de Salud; decidió reforzar el plan de vacunación.

Además, a partir del 2010 se ha detectado un aumento de los casos de parotiditis epidémica en el país que afecta de preferencia a adolescentes. Esta enfermedad comparte algunas de las características epidemiológicas del sarampión y hay diversos obstáculos para su control, entre los que destaca el agotamiento de la inmunidad post vacuna en un curso, probablemente no superior a 20 años. Con los antecedentes expuestos, pese a que se requiere de mayor investigación, se ha propuesto una revacunación del adolescente administrando una tercera dosis de vacuna trivírica.

\section{Problema global de Salud Pública}

Se estima que a nivel mundial el sarampión está circulando en más de 160 países. La enfermedad tiene una propagación sin precedentes, los viajeros infectados en el extranjero son fuente frecuente de transmisión del virus causando brotes periódicos. Chile es uno de los países que el 2017 no se reportaron casos y que en el 2018 sí hubo casos (Tabla 3) ${ }^{20}$. Según la OMS, en Europa los casos pasaron a 41.000 , alcanzando una cifra récord de aumento en 2018. La mitad de ellos ocurrido en Ucrania (Tabla 4) ${ }^{20}$. Estados Unidos no ha estado libre. En el año 2018 se reportaron 17 brotes en varios

\begin{tabular}{lc}
$\begin{array}{l}\text { Tabla 3. Casos de sarampión el 2018, en países que } \\
\text { el } \mathbf{2 0 1 7} \text { no reportaron } \text { casos }^{\mathbf{2 0}}\end{array}$ \\
\hline País & $\mathrm{n}$ de casos \\
\hline Brasil & 10.262 \\
Moldavia & 312 \\
Montenegro & 203 \\
Colombia & 188 \\
Timor Oriental & 59 \\
Perú & 38 \\
Chile & 23 \\
Uzbekistán & 17 \\
\hline
\end{tabular}

Tabla 4. Países con el mayor incremento de casos de sarampión entre 2017 y 2018 (20)

\begin{tabular}{lc}
\hline País & $\mathrm{n}$ de casos \\
\hline Ucrania & 30.338 \\
Filipinas & 13.192 \\
Brasil & 10.262 \\
Yemen & 6.641 \\
Venezuela & 4.916 \\
Serbia & 4.355 \\
Madagascar & 4.307 \\
Sudán & 3.496 \\
Tailandia & 2.758 \\
\hline
\end{tabular}


estados, siendo el brote más reciente notificado el 30 de diciembre que se extendió por varias semanas en Portland, Oregon, propagándose a los estados vecinos ${ }^{21}$ y recientemente se reportó un estado de emergencia en Nueva York.

A nivel mundial, según la OMS, los casos reportados en el 2018 fueron aproximadamente 229.000, pero reconocen que las estadísticas oficiales apenas representan el $10 \%$ de la realidad.

La OMS, en enero de 2019, ha advertido que los casos a nivel global han aumentado en $30 \%$ en los últimos años, llamando la atención sobre las consecuencias de la existencia de movimientos anti-vacunas y la renuncia de la gente, por ignorancia y desconocimiento de la enfermedad, o razones pseudo-científicas, a vacunarse $^{22}$. En Estados Unidos hay entidades que, por creencias filosóficas, no médicas, permiten excepción de vacunas infantiles. La tasa más alta de excepciones no médicas se identificó en 15 zonas metropolitanas y Portland fue una de ellas. Una publicación estimuló estos hechos. En 1998 Andrew Wakefield y colegas publicaron en la revista The Lancet un grupo de $12 \mathrm{ni}$ ños con autismo sugiriendo una relación causal con la vacuna tres vírica que habían recibido. La publicación generó un gran impacto mediático y de investigaciones pese el reducido número de pacientes, la falta de un grupo control y resultados opuestos a los de otras investigaciones. Muy pronto, 10 de los 12 autores cuestionaron la interpretación de los datos y, además, The Lancet denunció conflictos financieros de interés de Wakefield ${ }^{23}$. El 11 de febrero del 2010 la revista reconoció que los resultados publicados eran falsos ${ }^{24}$, su autor fue acusado de fraude deliberado y reconoció su falsedad ${ }^{25,26}$. Una reciente publicación poblacional en Dinamarca, descarta la asociación entre la vacuna trivírica y el riesgo de autismo ${ }^{27}$.
Katherine O’Brian, directora de inmunizaciones de la OMS indica: "estamos retrocediendo en los procesos que se iniciaron para prevenir el sarampión, no porque no tengamos herramientas para hacerlo sino por el fracaso en vacunar" 28 .

\section{Conclusiones}

Según la información disponible a la fecha, el sarampión está circulando en casi todo el mundo, incluso en Europa y Estados Unidos. La infección ha tenido un nivel de propagación sin precedentes. La OMS reconoce que las estadísticas oficiales no reflejan la realidad, con un grave riesgo de enfermedad y muerte de los niños. Antes de la vacunación, la enfermedad no era controlable, pero desde 1964 se dispone de una vacuna de alta eficacia cuya principal limitante es la necesidad de coberturas elevadas y mantenidas. Su no cumplimiento ha generado un grave problema de Salud Pública global. A ello se suma la ignorancia de la gente para quienes el sarampión es una enfermedad desconocida y los grupos anti vacunas que por diversas razones no médicas, se oponen a la vacunación de sus hijos. Hay que destacar el impacto mediático que aún persiste, generado por una publicación de hace 21 años que sugirió una relación causal entre autismo y la vacunas tres vírica, sobre la cual, incluso su autor debió reconocer su falsedad.

${ }^{* *}$ Los datos presentados tienen cambios casi diarios.

\section{Conflicto de intereses}

Los autores declaran no tener conflicto de intereses.

\section{Referencias}

1. Markowitz L, Katz M. Measles Vaccine En: S. A. Plotkin and E. A. Mortimer, Jr. (eds.), Vaccines. Philadelphia, Pa: The W. B. Saunders Co.; 1994. P. 229-76.

2. Panum P. Observaciones realizadas durante la epidemia de sarampión en las islas Faroe en 1846. En: Buck, C, Llopis A, Najera E, Terris M, eds. El desafío de la epidemiología. Washington DC: Organización Panamericana de la Salud; 1989. P. 38-42.

3. Laval E. La epidemia de sarampión de 1899-1900 en Chile y la creación del primer hospital de niños. Rev Chil Infectol 2002;19(2):121-3.

4. Repetto G. Sarampión. En: Repetto G: Enfermedades infecciosas inmunoprevenibles. Santiago Ediciones: Ediciones Universidad Católica de Chile; 2003. p. 313-33.

5. Krugman S, Giles J, Friedman H, et al. Studies in immunity to measles J Pediatr 1965;66:471-88.

6. Black F. The role of herd immunity in control of measles. The Yale J Biol and Medic 1982; 55: 351-60.

7. Lennon F, Black F. Maternally derived measles immunity in the era of vaccineprotected mothers J Pediatr 10(1);1986: 671-6.

8. Markowitz L. Persistence of measles antibody after revaccination. J Infect Dis 1992;166: 295-308.

9. Orenstein W, Bernier R. Surveillance. Information for action. Pediatr $\mathrm{Cl}$ North Am 1990;37: 709-34.
10. Valenzuela M, Leal I, Toro J, Vigilancia epidemiológica del sarampión en Chile. En: Jiménez J: "Control del sarampión en Chile”. Campaña Nacional de Inmunización 1992. Santiago, Dolmen, 1995:145-62.

11. Pan American Health Organization. Report to the Global Advisory Group of the Expanded Program on Immunization. Current impact of measles in Latin America. Washington, DC, 1981.

12. Delpiano L, Artoza L, Toro J. La enfermedad, epidemiología y los programas de vacunación en Chile. Rev Chil Infectol 2015;32(4):417-29.

13. Repetto G, Soza G. Mortalidad en la niñez debida a enfermedades prevenibles mediante vacunas. Rev Med Chile 1974; 102(7):550-8. 
14. Barja S., Repetto G., Saenger A. Sarampión en Chile. 1960-1985. Bol Esc Med Pont Univ Cat Chile 1987;17(3);348.

15. Repetto G, Barja S, Saenger A. Sarampión en el adulto. Consecuencia no prevista de la vacunación. Rev Med Chile 1987; 115(11):1102-8.

16. Ristori C, Boccardo H, Borgoño J, Armijo R. Medical importance of measles in Chile. Am J Dis Child 1962;103(3):23641.

17. Ristori C, Broccardo H, Miranda, et al. Vacunación contra el sarampión con virus vivos de la cepa Edmonston: experiencia nacional. Rev Chil Pediatr. 1963;34(11): 656-63.

18. Ministerio de Salud de Chile. Minsal inicia campaña de vacunación contra el sarampión, 2019. https://www.minsal.cl/ minsal-inicia-campana-de-vacunacioncontra-el-sarampion/

19. Black F, Berman L, Borgoño J, et al. Geographic variations in infant loss of maternal measles antibody and in the prevalence of rubella antibody. Am J Epidemiol 1986;124:442-52.

20. Dyer O. Measles: alarming worldwide surge seriously threatens children, says UN. BMJ 2019; 363:I981.

21. Flaccus G. Measles outbreak grows in Northwest US, 31 cases reported. AP News. 26 de Enero, 2019 https://www.apnews.com/ f97143eda2d14d78b8e54cfe281f9b62.

22. El Mercurio. La OMS y las Vacunas. Editorial El Mercurio 28 de Enero 2019. https://digital. elmercurio.com/2019/01/28/A/ RG3HBCH5\#zoom=page-width
23. Horton R. A statement by the editors of The Lancet. Lancet 2004; 363 (9411): 820-1.

24. DeStefano F, Chen RT. Negative association between MMR and autism. Lancet 1999;353(9169):1987-8.

25. Der B. Secrets on the MMR scare. How the vaccine crisis was meant to make money. BMJ 2011;342:c52-8.

26. Godlee F. The fraud behind the MMR scare. BMJ 2011; 342: d22.

27. Hvidd A, Hansen J, Frisch M, Melbye M. Measles, Measles, Mumps, Rubella Vaccination and Autism: A Nationwide Cohort Study. Ann Intern Med. 2019;170:513-20.

28. O Brian K. Measles cases nearly doubled in a year, UN health agency projects. UN News. 14 de Febrero, 2019 https://news. un.org/en/story/2019/02/1032771. 